\title{
Unexpected Symptomatic Pneumonitis Following Breast Tangent Radiation: A Case Report
}

\author{
Jessica L. Conway ${ }^{1}$, Karen Long ${ }^{2}$, Nicolas Ploquin ${ }^{3}$, Ivo A. Olivotto ${ }^{4}$ \\ 1. Radiation Oncology, Princess Margaret Cancer Centre, Toronto, ON 2. Department of Oncology, Tom \\ Baker Cancer Centre, Calgary 3. Department of Medical Physics, Tom Baker Cancer Centre, Calgary 4. \\ Department of Oncology, University of Calgary/Tom Baker Cancer Center
}

$\square$ Corresponding author: Jessica L. Conway, jessica.conway@rmp.uhn.ca Disclosures can be found in Additional Information at the end of the article

\section{Abstract}

Symptomatic radiation pneumonitis (RP) following radiation therapy (RT) to the breast alone is very uncommon. We report a case of an 80-year-old female who presented with fatigue, exertional dyspnea, fever, and cough 11.5 weeks following adjuvant breast RT with tangent fields alone. Imaging was consistent with RP, and she responded to a tapering course of steroids.

Categories: Radiation Oncology, Oncology

Keywords: breast cancer, radiation pneumonitis

\section{Introduction}

Radiation pneumonitis (RP) is a well-recognized toxicity following irradiation of the lung. The risk of RP following external beam RT for breast cancer varies with the volume of lung treated [1-3]. Patients typically present with a cough, dyspnea, low-grade fever, and occasionally chest pain. Pulmonary function tests may be normal. RP typically occurs within one to six months following completion of RT [2]. The MA20 trial reported clinical RP rates of $1.2 \%$ for locoregional RT (breast, axillary lymph nodes, and internal mammary chain [IMC]) and $0.2 \%$ for breast only treatment [4]. Additionally, the EORTC 22922 trial reported a higher incidence of clinical RP in patients who received locoregional RT (breast, IMCs and medial supraclavicular fields) compared to those receiving breast only treatment (0.7\% vs. $0.1 \%$, respectively) [5]. Here, we report a case of RP arising 11.5 weeks after adjuvant radiation to the breast alone.

Received 09/29/2015 Review began 10/07/2015 Review ended 10/14/2015 Published 10/22/2015

\section{(c) Copyright 2015}

Conway et al. This is an open access article distributed under the terms of the Creative Commons Attribution License CC-BY 3.0., which permits unrestricted use, distribution, and reproduction in any medium, provided the original author and source are credited.

\section{Case Presentation}

An 80-year-old female presented with a pT1c $(1.3 \mathrm{~cm})$ pN0 (two negative sentinel nodes), Grade 2, lobular carcinoma of the upper inner quadrant of the left breast detected incidentally on a CT scan for follow-up of colitis. Estrogen receptor status were 6/8, progesterone receptors 6/8 (both using the Allred scale), and the HER-2 gene was not over-expressed [6-7]. The lateral and posterior margins were $<1 \mathrm{~mm}$. Co-morbidities included a 25 -year history of colitis not associated with inflammatory bowel disease, hypertension, hypothyroidism, and osteopenia. Our patient had a diagnostic CT scan of the chest six months before RT with no radiographic evidence of pre-existing lung disease.

Informed patient consent was obtained prior to treatment. No reference to the patient's identity is present in this paper. 


\section{Cureus}

She declined endocrine therapy and was treated with RT to the left breast using a deep inspiration breath hold technique (DIBH) commencing 10 weeks after surgery. The radiation dose was 42.5 Gy in 16 fractions using a mixed 6 and 15 MV photon tangent pair, followed by a boost of $10 \mathrm{~Gy}$ in four fractions using $6 \mathrm{MeV}$ electrons. The mean lung dose (MLD) was $4.32 \mathrm{~Gy}$ and the volumes of ipsilateral lung receiving $\geqslant 5 \mathrm{~Gy}, \geqslant 20 \mathrm{~Gy}$, and $\geqslant 30 \mathrm{~Gy}$ were $17 \%$, 7\%, and $6 \%$, respectively (Figure 1). She developed brisk erythema of the skin overlying the axillary tail, but otherwise, the treatment course was uneventful. She started $3 \mathrm{mg}$ of budesonide (an orally administered corticosteroid) daily for colitis seven weeks following completion of RT. She discontinued the corticosteroid after 4.5 weeks without a tapering schedule.

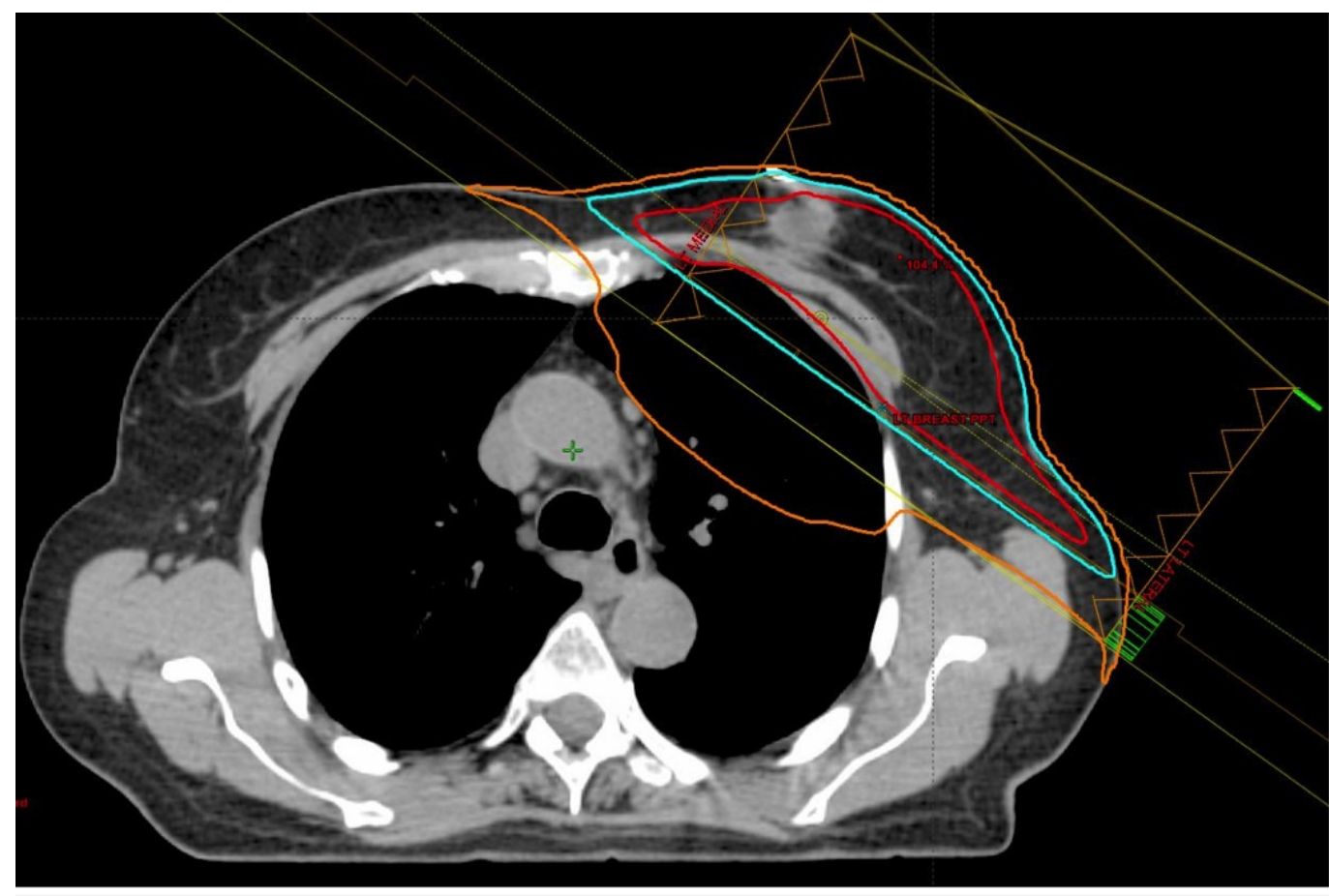

\section{FIGURE 1: Radiation treatment planning CT scan demonstrating the $95 \%$ (red inner line), $\mathbf{5 0 \%}$ (cyan middle line) and $5 \%$ (orange outer line) isodoses.}

Commencing 11.5 weeks after completion of RT (15 weeks from the start of RT) she noticed increasing fatigue, exertional dyspnea, fever, and cough. Two chest x-rays at 13.5 and 15.5 weeks from the completion of RT both confirmed left-sided consolidation favouring either pneumonia or a radiation reaction (Figure 2). Treatment with appropriate antibiotics failed to resolve her symptoms, which progressed over the next two weeks. On examination, moist rales were appreciated over the anterior left chest. She was not short of breath at rest. A repeat CT simulation scan using DIBH was performed in the treatment position to compare the consolidation location with the original treatment plan. The repeat CT scan was merged with the treatment planning CT, and the dosimetry and treatment fields were imported onto the new CT scan. The CT demonstrated consolidation in the anterolateral aspect of the left lung, which extended slightly above where the radiation volume projected onto the chest wall and terminated inferiorly at the lower field edge (Figure 3). 


\section{Cureus}

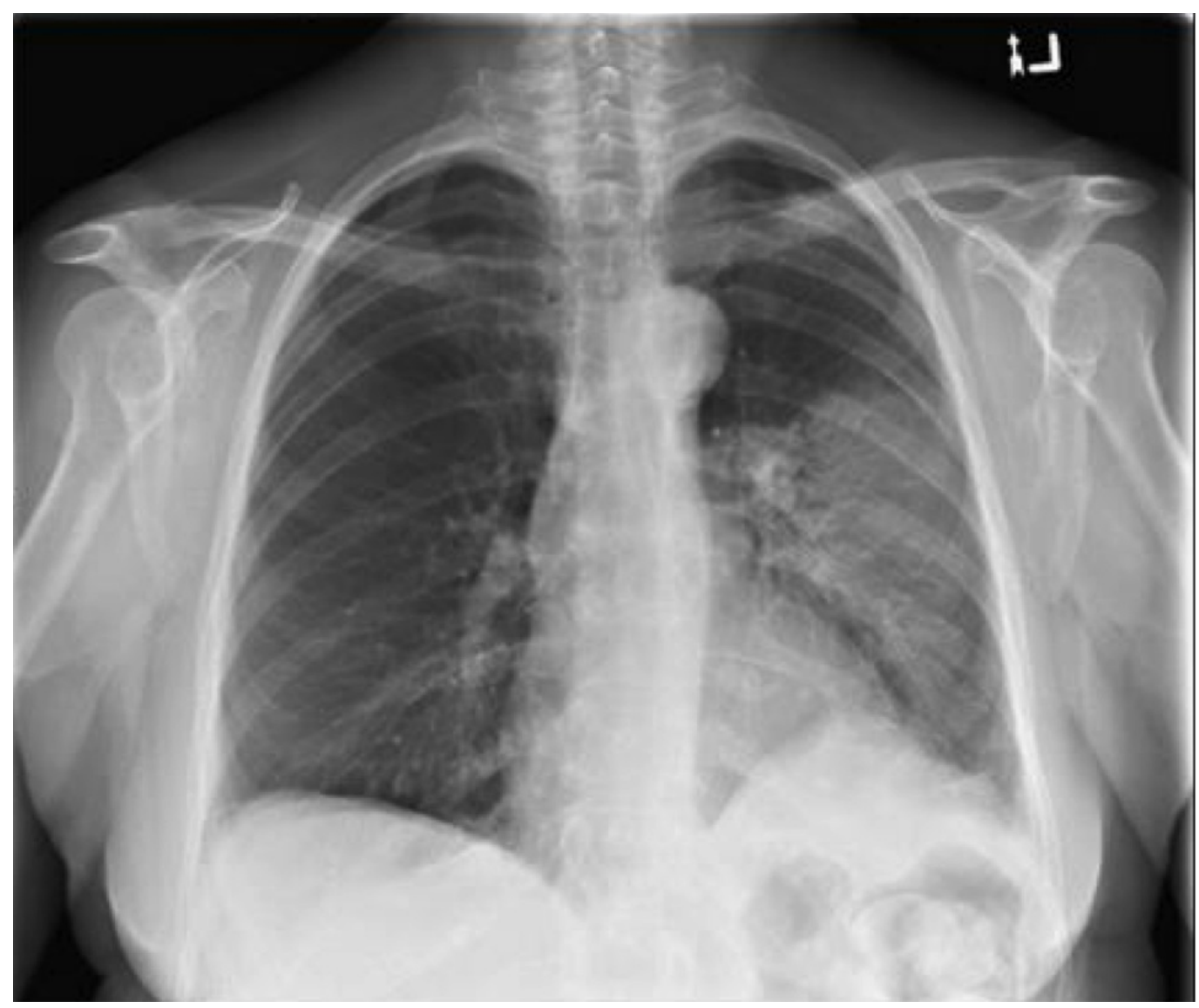

FIGURE 2: PA chest $x$-ray 14 weeks following completion of RT showing patchy consolidation in the central aspect of the left lung. 


\section{Cureus}

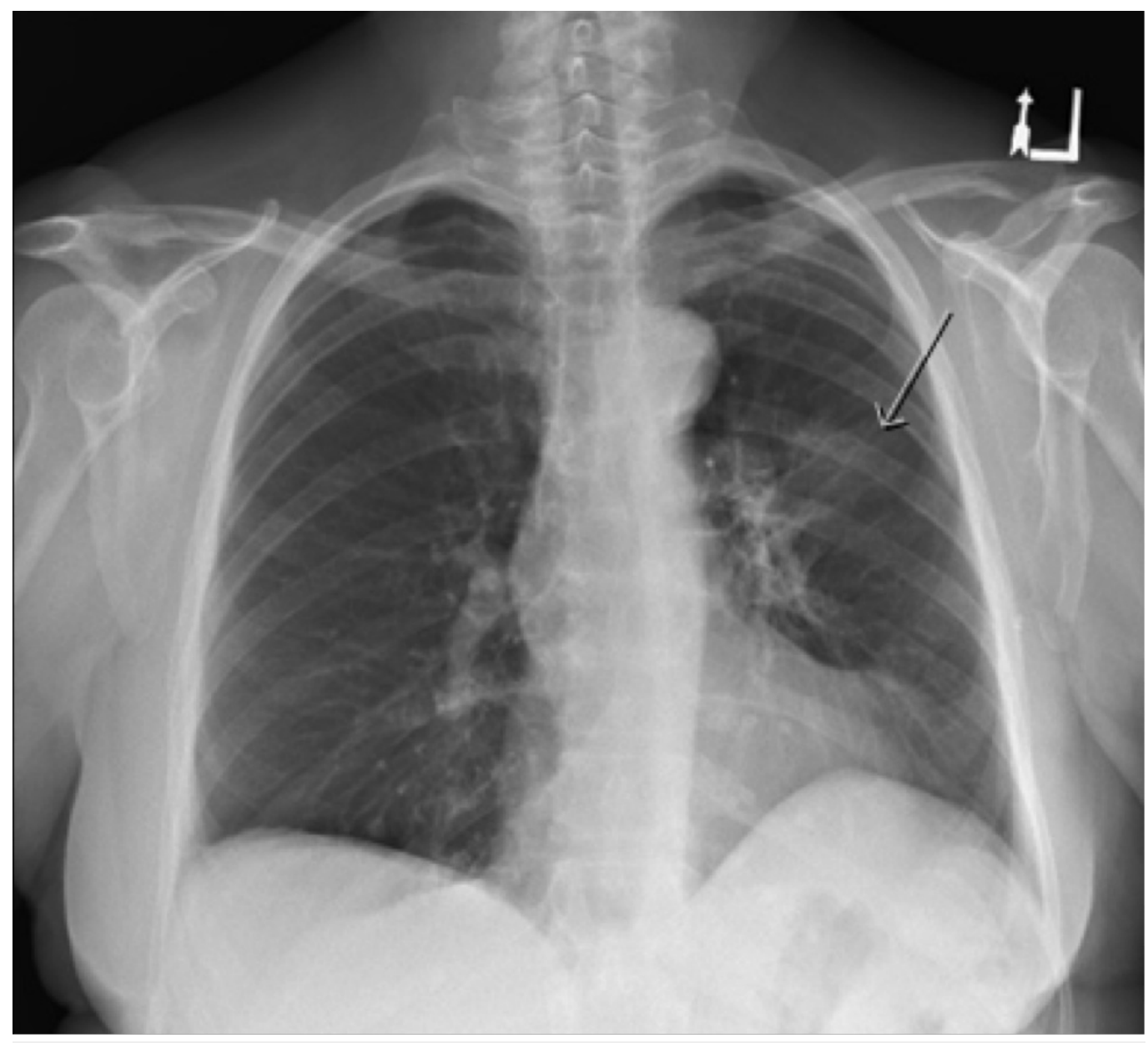

FIGURE 3: PA chest x-ray 4 weeks after starting prednisone showing significant improvement with some persistent airspace consolidation within the left upper lobe anteriorly.

Two certified medical physicists independently reviewed the treatment plan and delivery parameters and confirmed that treatment delivery was as intended. The radiographic appearance, along the tangential irradiated fields and the time interval from RT, favoured RP rather than cryptogenic organizing pneumonia (COP). She started $40 \mathrm{mg}$ of prednisone daily with prompt improvement in symptoms over one week. The dose of prednisone was tapered by $5 \mathrm{mg}$ every six days. A chest x-ray completed four weeks after commencing prednisone showed significant improvement with some persistent airspace consolidation (Figure 4). 


\section{Cureus}
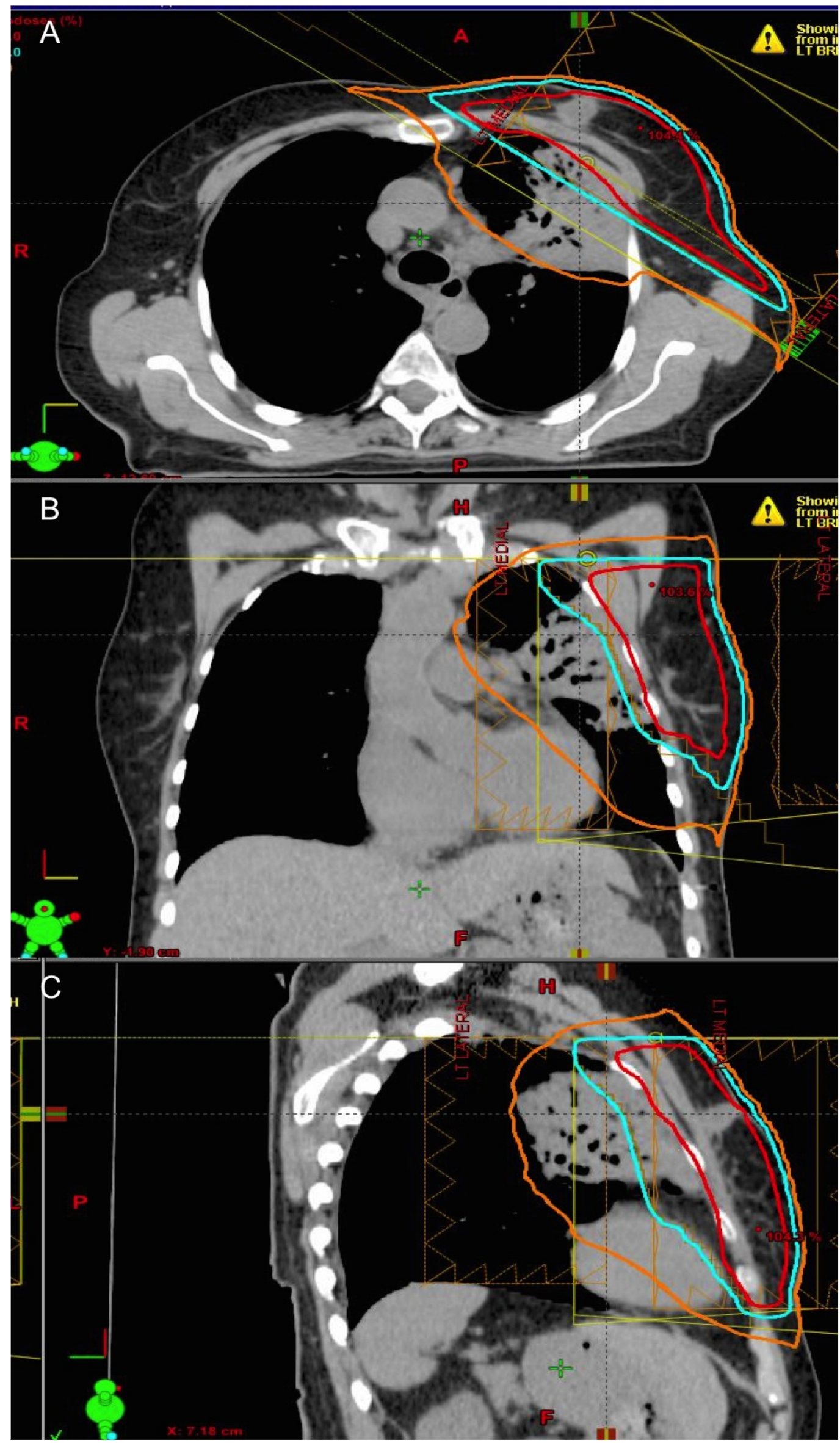

FIGURE 4: Post-RT CT simulation scan fused with the radiation 


\section{Discussion}

The consequences of RP include acute symptoms, permanent lung fibrosis, and possible longterm respiratory symptoms. Cases of fatal RP have been reported [8]. RT damages small vessels and capillaries, causing vascular congestion with increased capillary permeability. The resultant inflammation promotes pulmonary capillary obstruction by platelets, fibrin, and collagen resulting in the development of permanent fibrosis [2]. Several risk factors for radiation-induced pulmonary injury have been reported. These include irradiation of the lower lobe, advancing age, pre-existing pulmonary dysfunction, specific chemotherapeutic agents, concurrent endocrine therapy, steroid withdrawal, previous RT, increasing radiation dose, increasing normal lung volume irradiated, and use of twice-daily irradiation [2-3, 9-11].

Generally, adverse dosimetric data, such as a higher MLD and V20, increase the risk of RP [9, 12]. Kwa, et al. reported that MLD could assist in the prediction of RP in a cohort of 540 patients, of which 59 had breast cancer [13]. However, no consistent dosimetric parameter has been identified. In our case, the ipsilateral lung V20 Gy was only 7\%, a dose-volume that one would not expect to result in symptomatic RP. Furthermore, there were no radiographic characteristics of interstitial lung disease, which might have increased her risk of pulmonary toxicity. The risk of clinical RP following breast alone, tangential RT is 1-2 per thousand [45]. This suggests that individual genetic variation may explain the occurrence of RP in some individuals. In the lung cancer literature, an association between clinical RP and both methylenetetrahydrofolate reductase (MTHFR) genotype and ataxia telangiectasia mutated (ATM) polymorphisms has been described [14-16].

Steroid withdrawal RP has been reported in the literature resulting from a discontinuation or rapid reduction in steroid treatments in patients who have received radiation. This phenomenon has traditionally been associated with malignant lymphomas. However, there are case reports of patients treated with RT for carcinomas who developed RP following discontinuation of steroids [17]. In our patient, the abrupt discontinuation of budesonide coincided with the development of symptomatic RP. This may have exacerbated her respiratory symptoms and predisposed our patient to RP. Many patients with breast cancer receive taxanebased chemotherapy with dexamethasone support as an anti-emetic. That amount of steroid medication has not been associated with an increased risk of symptomatic RP.

Pulmonary toxicity in patients treated with chest wall RT can occur with several different patterns, including radiation pneumonitis as described above, COP, and radiation recall pneumonitis (RPP). COP is a form of sub-acute lung damage, which typically occurs within one year after completion of RT. It is characterized by lung infiltrations extending outside of the RT fields and does not result in pulmonary fibrosis $[10,18]$. COP has a higher incidence in breast cancer than other malignancies [18]. RPP develops subsequently to the use of an antineoplastic agent in patients many years following RT [10]. Our patient had consolidation of the lingula, but no overt radiographic signs to suggest COP.

Identifying patients who are at increased risk of RP is a challenge due to the lack of consistent predictive factors and since no ideal dosimetric parameters have been identified. Improvements in radiation techniques, including the use of DIBH to reduce lung V20, may help decrease the risk of RP [19-20]. However, in our case, despite advanced technology, the use of DIBH, and excellent lung dosimetric parameters, the occurrence of symptomatic RP was not prevented. 
This suggests an idiosyncratic reaction or unknown factors contributed to the development of RP.

\section{Conclusions}

Our report describes a case of symptomatic RP occurring 11.5 weeks following adjuvant radiation to the breast with tangents alone. Dosimetric parameters included an ipsilateral lung V20 of only 7\% and a MLD of $4.32 \mathrm{~Gy}$. Although RP is uncommon following breast alone RT, it is a real risk and should be discussed with patients.

\section{Additional Information Disclosures}

Human subjects: Consent was obtained by all participants in this study. Conflicts of interest: In compliance with the ICMJE uniform disclosure form, all authors declare the following: Payment/services info: All authors have declared that no financial support was received from any organization for the submitted work. Financial relationships: All authors have declared that they have no financial relationships at present or within the previous three years with any organizations that might have an interest in the submitted work. Other relationships: All authors have declared that there are no other relationships or activities that could appear to have influenced the submitted work.

\section{References}

1. McDonald S, Rubin P, Phillips TL, Marks LB: Injury to the lung from cancer therapy: clinical syndromes, measurable endpoints, and potential scoring systems. Int J Radiat Oncol. 1995, 31:1187-1203. 10.1016/0360-3016(94)00429-O

2. Stover DE, Kaner RJ: Pulmonary toxicity. DeVita, Hellman and Rosenberg’s Cancer: Principles \& Practice of Oncology, 9th edition. DeVita VT, Lawrence TS, Rosenberg SA (ed): Lippincott Williams \& Wilkins, Philadelphia, Pa; 2011. 2348-59.

3. Lind PA, Marks LB, Hardenbergh PH, Clough R, Fan M, Hollis D, Hernando ML, Lucas D, Piepgrass A, Prosnitz LR: Technical factors associated with radiation pneumonitis after local \pm regional radiation therapy for breast cancer. Int J Radiat Oncol. 2002, 52:137-43.

10.1016/S0360-3016(01)01715-1

4. Whelan TJ, Olivotto IA, Parulekar WR, Ackerman I, Chua BH, Nabid A, Vallis KA, White JR, Rousseau P, Fortin A, Pierce LJ, Manchul L, Chafe S, Nolan MC, Craighead P, Bowen J, McCready DR, Pritchard KI, Gelmon K, Murray Y, Chapman JA, Chen BE, Levine MN; MA.20 Study Investigators: Regional nodal irradiation in early-stage breast cancer . N Engl J Med. 2015, 373:307-316. 10.1056/NEJMoa1415340

5. Matzinger O, Heimsoth I, Poortmans P, Collette L, Struikmans H, Van Den Bogaert W, Fourquet A, Bartelink H, Ataman F, Gulyban A, Pierart M, Van Tienhoven G, EORTC Radiation Oncology \& Breast Cancer Groups: Toxicity at three years with and without irradiation of the internal mammary and medial supraclavicular lymph node chain in stage I to III breast cancer (EORTC trial 22922/10925). Acta Oncol. 2010, 49:24-34. 10.3109/02841860903352959

6. Allred DC, Harvey JM, Berardo M, Clark GM: Prognostic and predictive factors in breast cancer by immunohistochemical analysis. Mod Pathol. 1998, 11:155-68.

7. Wolff AC, Hammond ME, Hicks DG, Dowsett M, McShane LM, Allison KH, Allred DC, Bartlett JM, Bilous M, Fitzgibbons P, Hanna W, Jenkins RB, Mangu PB, Paik S, Perez EA, Press MF, Spears PA, Vance GH, Viale G, Hayes DF, American Society of Clinical Oncology, College of American Pathologists: Recommendations for human epidermal growth factor receptor 2 testing in breast cancer: american society of clinical oncology/college of american pathologists clinical practice guideline update. J Clin Oncol. 2013, 31:3997-4013. 10.1200/JCO.2013.50.9984

8. Palma DA, Senan S, Tsujino K, Barriger RB, Rengan R, Moreno M, Bradley JD, Kim TH, Ramella S, Marks LB, De Petris L, Stitt L, Rodrigues G: Predicting radiation pneumonitis after chemoradiation therapy for lung cancer: an international individual patient data meta- 
analysis. Int J Radiat Oncol Biol Phys. 2013, 85:444-50. 10.1016/j.ijrobp.2012.04.043

9. Mehta V: Radiation pneumonitis and pulmonary fibrosis in non-small-cell lung cancer:

Pulmonary function, prediction, and prevention. Int J Radiat Oncol Biol Phys. 2005, 63:5-24.

10.1016/j.ijrobp.2005.03.047

10. Omarini C, Thanopoulou E, Johnston SRD: Pneumonitis and pulmonary fibrosis associated with breast cancer treatments. Breast Cancer Res Treat. 2014, 146:245-58. 10.1007/s10549014-3016-5

11. Katayama N, Sato S, Katsui K, Takemoto M, Tsuda T, Yoshida A, Morito T, Nakagawa T, Mizuta A, Waki T, Niiya H, Kanazawa S: Analysis of factors associated with radiation-induced bronchiolitis obliterans organizing pneumonia syndrome after breast-conserving therapy. Int J Radiat Oncol. 2009, 73:1049-54. 10.1016/j.ijrobp.2008.05.050

12. Blom-Goldman U, Svane G, Wennberg B, Lideståhl A, Lind PA: Quantitative assessment of lung density changes after 3-D radiotherapy for breast cancer. Acta Oncol. 2007, 46:187-93. 10.1080/02841860600949586

13. Kwa SL, Lebesque JV, Theuws JC, Marks LB, Munley MT, Bentel G, Oetzel D, Spahn U, Graham MV, Drzymala RE, Purdy JA, Lichter AS, Martel MK, Ten Haken RK: Radiation pneumonitis as a function of mean lung dose: an analysis of pooled data of 540 patients. Int J Radiat Oncol Biol. 1998, 42:1-9. 10.1016/S0360-3016(98)00196-5

14. Mak RH, Alexander BM, Asomaning K, Heist RS, Liu CY, Su L, Zhai R, Ancukiewicz M, Napolitano B, Niemierko A, Willers H, Choi NC, Christiani DC: A single-nucleotide polymorphism in the methylene tetrahydrofolate reductase (MTHFR) gene is associated with risk of radiation pneumonitis in lung cancer patients treated with thoracic radiation therapy. Cancer. 2012, 118:3654-65. 10.1002/cncr.26667

15. Zhang L, Yang M, Bi N, Fang M, Sun T, Ji W, Tan W, Zhao L, Yu D, Lin D, Wang L: ATM polymorphisms are associated with risk of radiation-induced pneumonitis. Int J Radiat Oncol. 2010, 77:1360-68. 10.1016/j.ijrobp.2009.07.1675

16. Xiong H, Liao Z, Liu Z, Xu T, Wang Q, Liu H, Komaki R, Gomez D, Wang LE, Wei Q: ATM polymorphisms predict severe radiation pneumonitis in patients with non-small cell lung cancer treated with definitive radiation therapy. Int J Radiat Oncol. 2013, 85:1066-73.

10.1016/j.ijrobp.2012.09.024

17. Pezner RD, Bertrand M, Cecchi GR, Paladugu RR, Kendregan BA: Steroid-withdrawal radiation pneumonitis in cancer patients. Chest. 1984, 85:816-17. 10.1378/chest.85.6.816

18. Oie Y, Saito Y, Kato M, Ito F, Hattori H, Toyama H, Kobayashi H, Katada K: Relationship between radiation pneumonitis and organizing pneumonia after radiotherapy for breast cancer. Radiat Oncol. 2013, 8:56. 10.1186/1748-717X-8-56

19. Remouchamps VM, Vicini FA, Sharpe MB, Kestin LL, Martinez AA, Wong JW: Significant reductions in heart and lung doses using deep inspiration breath hold with active breathing control and intensity-modulated radiation therapy for patients treated with locoregional breast irradiation. Int J Radiat Oncol Biol Phys. 2003, 55:392-406. 10.1016/S03603016(02)04143-3

20. Nissen HD, Appelt AL: Improved heart, lung and target dose with deep inspiration breath hold in a large clinical series of breast cancer patients. Radiother Oncol. 2013, 106:28-32. 10.1016/j.radonc.2012.10.016 